\section{Afferent Paresis}

Maryellen Romero

Department of Psychiatry and Behavioral

Sciences, Tulane University School of Medicine,

New Orleans, LA, USA

\section{Definition}

A deficit in the ability to perform voluntary movements due to loss of kinesthetic feedback. The primary and secondary motor cortices have extensive inputs from the somatosensory areas in the parietal lobes. Following lesions to this latter area, particularly the post-central gyrus or to the lemniscal system which provides proprioceptive information to it, motor difficulties may be observed either in the limbs or in speech production. Although the muscles involved in such activities are not weak per se, the loss of sensory information results in a disruption of motor control and an imprecise excitation of muscle groups required to execute specific, voluntary fine-motor responses.

\section{Cross-References}

Lemniscal System

\section{References and Readings}

Luria, A. L. (1976). The working brain: An introduction to neuropsychology. New York: Perseus Books Group. 